\title{
Letter
}

\section{Friction in sliding heavy objects on ice}

In cold regions, sledges have been used for transport since ancient times. Even today they are used to move heavy loads for example at the McMurdo Antarctic station. Of course, understanding sliding friction on ice is important in modern transportation due to the slipperiness of icy roads.

In a recent article, the method by which huge stones were transported to the Forbidden City during its construction in the 15th and 16th centuries was revealed by $\mathrm{Li}$ and others (2013) to be sliding a sledge on an artificial ice path. They claim that the ice required lubrication, in order to reduce the friction to the necessary level. Does ice really need to be lubricated to make it slippery?

The technique of lubricating ice by water was analysed by $\mathrm{Li}$ and others (2013) in detail, concluding that wood-on- ice sliding was more reliable and efficient than other transportation methods, but that pouring water on the contact surface was necessary to make this type of transport feasible. The lubricating technique used of the Chinese was further discussed by Schulson (2013), who also concluded that controlled lubrication by water was necessary.

Without lubrication, the coefficient of kinetic friction on ice, under the postulated conditions (temperature $-3.7^{\circ} \mathrm{C}$, sliding velocity $8 \mathrm{~cm} \mathrm{~s}^{-1}$ ), would have been 0.22 according to Li and others (2013) and Schulson (2013). They refer to Bowden's classical paper. However, we are unable to find any such data from that paper. Bowden (1953) provides the static friction coefficient of 0.24 for ski lacquer in Table 2 and points out, based on Table 5 that the kinetic friction coefficient at $3 \mathrm{~cm} \mathrm{~s}^{-1}$ and $-10^{\circ} \mathrm{C}$ is typically $10 \%$ lower than the static friction coefficient. However, such conditions are very different from those discussed by Li et al. (1).

We have made measurements on the friction coefficient of wood on ice. We used a $40 \mathrm{~mm} \times 40 \mathrm{~mm}$ planed piece of hickory (density $750 \mathrm{~kg} \mathrm{~m}^{-3}$, thermal conductivity $0.19 \mathrm{~W} \mathrm{~m}^{-2} \mathrm{~K}^{-1}$, heat capacity $1.4 \mathrm{~kJ} \mathrm{~kg}^{-1} \mathrm{~K}^{-1}$ ) sliding it linearly on a smooth ice plate in a cold room facility. The measurement equipment and procedures are described in Rantonen and others (2012). We made experiments at the sliding speed of $8 \mathrm{~cm} \mathrm{~s}^{-1}$, estimated as representative of the transport by the Chinese (Li and others, 2013; Schulson, 2013), and nominal normal forces 200, 410, 820, $1120 \mathrm{~N}$, which cover the postulated pressure range for transporting a $120-300 \mathrm{t}$ stone by a sledge ( $\mathrm{Li}$ and others, 2013). We used two cold room temperatures -2.8 and $-3.7^{\circ} \mathrm{C}$. All related equipment was stored in the cold room so that they adopted the same temperature.

The results of our linear sliding experiments show a coefficient of friction of $0.026(0.022 \pm 0.001)$ at $-2.8^{\circ} \mathrm{C}$ and $0.029(0.017 \pm 0.003)$ at $-3.7^{\circ} \mathrm{C}$. The values are those measured upon the first sliding on virgin ice and the values in the brackets represent the mean of 29 subsequent repeated slides along the same ice path. The effect of the normal force in this range was found negligible. We also made the wood surface rough by grinding, and in this case the coefficient of friction was $0.032(0.017 \pm 0.003)$ at $-2.8^{\circ} \mathrm{C}$. Finally, we flooded the ice by pouring cold water, so that a continuous water layer was formed. The coefficient of friction in these experiments using the planed wood was $0.036(0.028 \pm 0.004)$.

We have also developed a comprehensive numerical model of friction on ice (Makkonen and Tikanmäki, 2014). This model is based on thermodynamics and contact mechanics, and includes much more detailed physics than the simple calculations in the supplementary material by $\mathrm{Li}$ and others (2013). The model has been verified by experimental data of sliding of steel and rubber on ice, and also on ice/ice friction, in a wide range of conditions (Makkonen and Tikanmäki, 2014). We have run this model using the same postulated conditions and the material parameters for hickory, and obtain a coefficient of friction of 0.007. This is even smaller than our measured value, probably because of inaccuracy of ice hardness parameterization in the model this close to the melting temperature of ice.

In conclusion, we have shown both experimentally and theoretically that wood-on-ice coefficient of friction, under the conditions of transporting heavy stones to the Forbidden City in 1557 , is an order of magnitude lower than estimated earlier ( $L i$ and others, 2013; Schulson, 2013). The resisting force at a coefficient of friction as low as 0.03 corresponds to that on a $1.7^{\circ}$ upslope without any friction, showing that the practical problems that the Chinese were facing, such as the necessary manpower, were other than those caused by the small kinetic friction on ice. Our experiments and the theoretical model also indicate that lubrication by water, which has been believed to be necessary for sliding heavy loads on ice (Li and others, 2013; Schulson, 2013), actually increases the friction coefficient.

\section{ACKNOWLEDGEMENTS}

This work was supported by Academy of Finland, Grant no. 268925.

\author{
${ }^{1}$ Technical Research Centre \\ of Finland, PO Box 1000, 02044 \\ VTT, Espoo, Finland
}

LASSE MAKKONEN ${ }^{1}$ MARIA TIKANMÄKI ${ }^{1}$ PANU SAINIO ${ }^{2}$

\author{
${ }^{2}$ Aalto University, School of \\ Engineering, PO Box, 14100, 00076 \\ AALTO, Espoo, Finland \\ E-mail: Lasse Makkonen <lasse.makkonen@vtt.fi>
}

\section{REFERENCES}

Bowden FP (1953) Friction on snow and ice. Proc. R. Soc. London A, 217(1131), 462-478

Li J, Chen $\mathrm{H}$ and Stone HA (2013) Ice lubrication for moving heavy stones to the Forbidden City in 15th and 16th century China. Proc. Nat. Acad. Sci. USA, 110, 20023-20027

Makkonen L and Tikanmäki M (2014) Modeling the friction on ice. Cold Regions Sci. Technol., 102, 84-93

Rantonen M, Tuononen AJ and Sainio P (2012) Measuring stud and rubber friction on ice under laboratory conditions. Int. J. Veh. Syst. Model. Test., 7, 194-207

Schulson E (2013) Sliding heavy stones to the Forbidden City on ice. Proc. Natl. Acad. Sci. USA, 110, 19978-19979 